\title{
The predictive model for strength of inclined screws as shear connec- tion in timber-concrete composite floor
}

\author{
F. Moshiri, C. Gerber, H.R. Valipour, R. Shrestha \& K.I. Crews \\ Centre for built infrastructure, University of Technology Sydney, Australia
}

ABSTRACT: Interest in timber-concrete composite (TCC) floors has increased over the last 30 years. TCC technology relies on timber and concrete members acting compositely together. Both timber and concrete exhibit a quite brittle behaviour in bending/tension and compression respectively whilst the shear connection is identified as the only contributor of ductile behaviour. Therefore, the strength, stiffness and arrangement of the shear connection play a crucial role in the structural design of TCC. There are only few investigations on analytical closed-form equation to predict the stiffness and strength of TCC joints as input values to design a partially composite floor. For example, Johansen's yield theory was adopted as European yield model in Eurocode 5. However, the equations are limited to vertically inserted dowels or screws and Eurocode 5 recommends that the strength and stiffness of unconventional joints should be determined by push-out tests. Previous investigations reported that the inclined shear connector significantly increase the initial stiffness and ultimate strength of the TCC joints and consequently composite floor.

This paper presents a model for the strength of TCC joint using crossed $\left( \pm 45^{\circ}\right)$ proprietary screws (SFS Intec). The Johansen yield theory is extended to derive the strenght model of TCC joint with crossed $\left( \pm 45^{\circ}\right)$ screws which are loaded in tension and compression. The model is an upper bound plastic collapse model that assumes the behaviour of timber and screw perfectly plastic with undamaged concrete. The failure modes considers of yield of screw, in tension or shear, and some combined modes assuming screw withdrawal, lateral crushing of the timber and the development of plastic hinges in the screw. The experimental aspect of the research consists of push-out tests and aims to verify the strength model of TCC joints with inclined screws. The failure modes are also investigated. The model seems to be reasonably accurate in predicting both the characteristic strength and failure mode. This research suggests the model to facilitate the design of inclined screw shear connections for TCC construction.

\section{INTRODUCTION}

Timber concrete composites (TCCs) are structural elements that comprised of timber and concrete elements joined together by some form of shear connector. They are most commonly used as floor systems. Mechanical fasteners are typically used and there are a number of different types of connectors available with varying effectiveness, price and labour requirement (Kieslich \& Holschemacher 2010). Fasteners include nails, screws, spikes, shear keys and proprietary devices. The degree of stiffness of the composite is dependent on the stiffness of the connection (Clouston et al. 2005). The connector allows for composite action - that is, for the timber and concrete to act together as one entity, with the timber action in tension due to bending and concrete acting in compression due to bending (Branco et al. 2007). This is aligned with the materials' natural properties and behaviours (Moshiri et al. 2012).

TCCs benefit from the composite action, resulting in a significant improvement in strength and stiffness compared to the timber and concrete acting independently (Clouston et al. 2005). The level of this benefit depends on the stiffness of the connector, and can range from no connection to rigid connection, with the boundaries of structural efficiency determined by these theoretical limits (Clouston et al. 2005; Kieslich \& Holschemacher 2010). The literature review of existing theoretical model and experimental investigation indicates that the inclination of 
the fasteners results in higher stiffness and strength rather than the perpendicular one.

The first part of this paper states the kinematic plastic collapse model adopted for inclined SFS screws connections. Finally the experimental data gained from push-out test are used to validate the analytical model. The paper concludes that the predicted model is in a good agreement with the experimental results.

\section{ANALYTICAL MODEL}

The load carrying capacity model of inclined fastener used in TCC joint is derived based on some modification to the European Yield Model (EYM) taking into account the withdrawal capacity of the screws as a result of the angle between the screw axis and the timber grain direction. The aforementioned model is an upper bound collapse load that complies with Johansen's yield theory which is adopted for inclined fasteners. In order to apply the kinematic plastic method using the principle of virtual work, the presumed shape at collapse is postulated as part of the compatible displacement set whilst the external and internal loads are considered as the equilibrium set.

The kinematic plastic method of TCC joint assumes that the work done by external load is equal to the energy absorbed by plastic deformation in the timber or/and any plastic hinges in the fastener

The external work $W_{E}$ done by the external force is the multiplication of collapse load by corresponding the slip at the interface of the concrete and timber as shown in Equation 1 whilst the internal energy $W_{I}$ dissipated by each failure modes is the internal work equal to the internal force times the localised displacement associated to each failure mode (Symon et al. 2010).

$$
W_{E}=R \Delta_{\text {lat }}
$$

Equating the external work and internal dissipated energy, an upper bound on the collapse load of each supposed mechanism is obtained. Therefore, the lowest collapse load and the corresponding failure mode govern the behaviour of the joint.

$W_{E}=W_{I}$

It is assumed that the fastener embedded in concrete is stiff enough to remain undeformed and the friction between the timber and concrete is considered negligible. The material properties of the screw in timber such as withdrawal, embedment strength and ultimate tensile stress of screw are however required to predict the load carrying capacity of joint.

\subsection{Mode 1 - the withdrawal failure of screw}

Mode 1 states the withdrawal of the screw from the timber component without any sign of crushing in the timber whilst Mode 2 indicates some horizontal displacement of fastener followed by crushing of the timber component (

Figure 1).

As discussed in Symon et al. (2010), in Mode 1, the screw is withdrawn from the timber without developing any crushing failure to the timber. Eurocode 5 puts forward Equation 3 to calculate the withdrawal strength of a screw perpendicular to the timber grain. In addition, Eurocode 5 proposes Equation 4 to obtain the withdrawal strength of screw inserted at an angle to the grain. Hence, axial withdrawal load capacity of inclined screw is calculated by introducing Equation 4 into Equation 5 where $t$ is the embedded length of the screw in the timber or according to Eurocode 5 as expressed in Equation 6 whereas, effective length, $l_{e f}$ is equal to $t$ $-d$ and $d$ is the thread diameter. The internal dissipated energy is derived using Equation 7. Equating the external work (Equation 1) and internal dissipated energy (Equation 7), the load-bearing capacity in failure Mode 1 is obtained as illustrated in Equation 9.

$$
\begin{aligned}
& f_{a, 0}=3.6 * 10^{-3} \rho_{k}^{1.5} \\
& f_{a, \alpha}=\frac{f_{\alpha, 0}}{\cos ^{2} \alpha+1.5 \sin ^{2} \alpha} \\
& F_{a x, \alpha}=\pi d t f_{a, \alpha} \\
& F_{a x, \alpha}=\left(\pi d l_{e f}\right)^{0.8} t f_{a, \alpha} \\
& W_{I}=F_{a x, \alpha} \Delta_{a x} \\
& \Delta_{a x}=\frac{\Delta_{l a t}}{\sin \alpha} \\
& R_{1}=\frac{F_{a x, \alpha}}{\sin \alpha}
\end{aligned}
$$

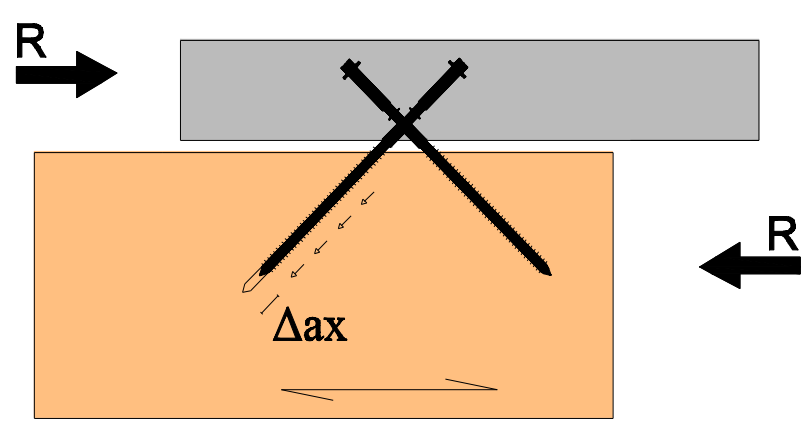

Figure 1 Mode 1 - screw withdrawn from timber.

\subsection{Mode 2 - lateral displacement of screw}

Mode 2 indicates the horizontal displacement of the screw which crushes the timber without forming a plastic hinge ( 
Figure 2). The load carrying capacity in failure Mode 2 is governed by the embedding strength of the surrounding timber. Eurocode 5, section 8.3 proposes Equation 10 to calculate the characteristic embedment strengths of nails and screws embedded in timber and LVL with predrilled holes.

$f_{h, 0, k}=0.082 \rho_{k}\left(1-0.01 d_{e f}\right)$

$W_{I}=f_{h, 0, k} d t \Delta_{l a t} \cos \alpha$

Again, equating the external work (Equation 1) and internal dissipated energy (Equation 11), the load carrying capacity in failure Mode 2 is obtained as proposed in Equation 12.

$R_{2}=f_{h, 0} d t \cos \alpha$

Where,

$\rho_{k}$ is the characteristic timber density, in $\mathrm{kg} / \mathrm{m}^{3}$;

$d$ is the screw diameter, in mm.

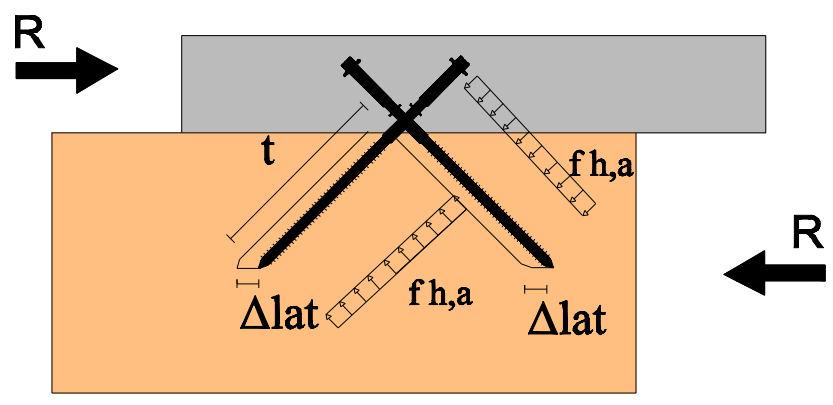

Figure 2 Mode 2 - lateral displacement of screw.

\subsection{Mode 3-combination of wood bearing failure and withdrawal of screw}

There is another possible failure mode which corresponds to the plastic yielding of the wood along the fastener. In this failure mode, the ultimate load carrying capacity is obtained by the work calculation in the non-deformed state of the screw as a combination of the withdrawal and embedding stresses.

Kavaliauskas \& Kvedaras (2010) stated that due to the different behaviour of embedded and withdrawal timber under the screw at the failure of connection the values of embedding and withdrawal stresses are not of the ultimate values. Therefore, ultimate load-carrying capacity is obtained by the work calculation of the non-deformed state of the screw as a combination of withdrawal and embedding stresses as proposed in Equation 13 (

Figure 3).

The values of embedding and withdrawal stresses vary with the inclination angle of the screw to the grain direction of the timber. At an angle of $90^{\circ}$, the embedding stress is equal to the embedding stress parallel to the grain without any withdrawal stress, whilst at an angle of $0^{\circ}$, the embedding stresses reaches zero with the maximum withdrawal stress (Kavaliauskas \& Kvedaras 2010).

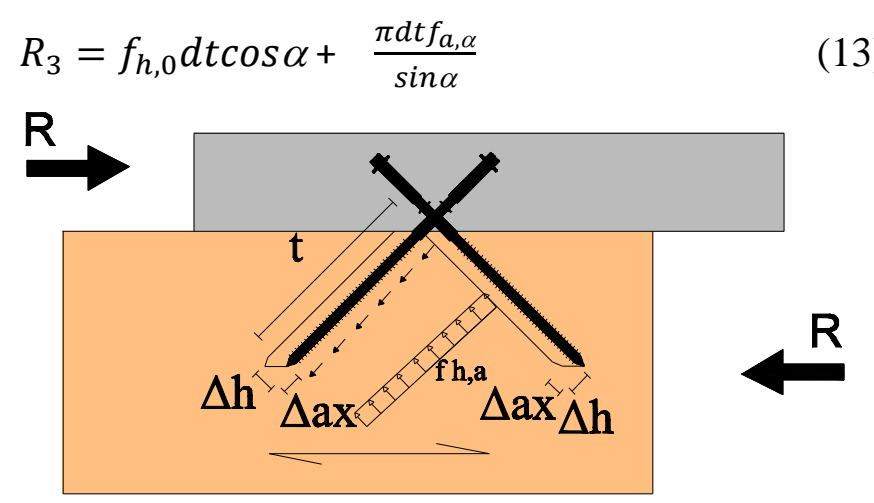

Figure 3 Mode 3- combination of wood bearing failure and withdrawal of screw.

\subsection{Mode 4 - single plastic hinge in screw}

Considering the dowel effect in Modes 4 and 5, Mode 4 represents a single plastic hinge at the timber-concrete interface whilst Mode 5 shows double plastic hinges - one at timber-concrete interface and one along the portion of the screw embedded in the timber (

\section{Figure 4).}

Eurocode 5 section 8.3 puts forward Equation 14 to calculate the yield moment My for round fasteners produced from wire with a minimum tensile strength of $600 \mathrm{~N} / \mathrm{mm}^{2}$.

$M_{y}=0.3 f_{u} d^{2.6}$

whereas,

$d$ is the nail diameter, in $\mathrm{mm}$;

$f_{u}$ is the tensile strength of the wire, in $\mathrm{N} / \mathrm{mm}^{2}$.

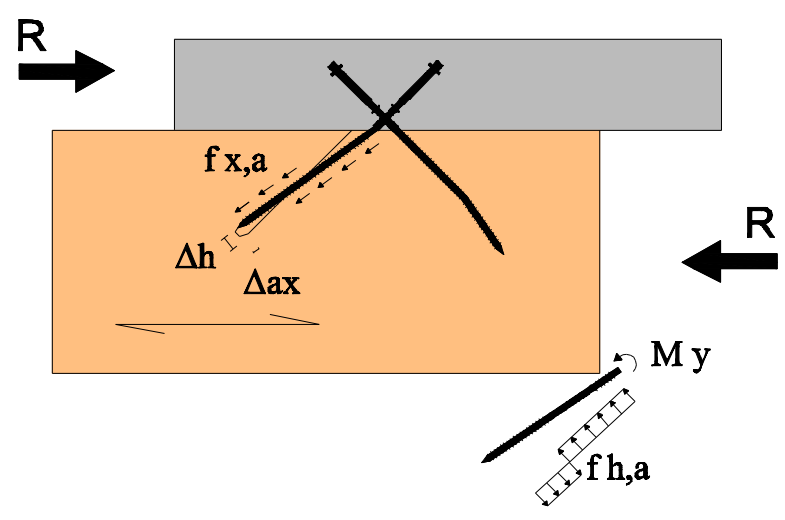

Figure 4 Mode 4 - single plastic hinge in screw.

The appropriate embedded length and distribution of the embedment stress along the screw results in the formation of plastic hinge at the timber-concrete 
interface. This failure coincides with a rigid rotation of the fastener about some point along the fastener which crushes the timber in front of the screw above the point of rotation and behind the screw below the point of rotation (Kavaliauskas et al. 2007; Symon et al. 2010) .

Satisfying the equilibrium of the moment about the timber-concrete interface, the distance between the rotation point and the interface of materials, $\mathrm{x}$ is calculated using Equation 15. The lateral displacement of the tip of the screw $\Delta_{\text {tip }}$ is then written as the function of lateral displacement and $\mathrm{x}$ as given in Equation 16.

$x=\sqrt{\frac{M_{Y}}{f_{h, a}}+\frac{t^{2}}{2}}$

$\Delta_{\text {tip }}=\frac{\Delta_{\text {lat }}(t-x)}{x}$

The internal energy which dissipated by the embedment in the timber, withdrawal of screw and rotation of the plastic hinge is shown in Equation 17.

$W_{I}=f_{h, \alpha} d \cos \alpha \frac{\Delta_{l a t}}{2}+f_{h, \alpha} d(t-x) \cos \alpha \frac{\Delta_{t i p}}{2}+$

$F_{a x, \alpha} \Delta_{\text {axial }}+M_{y} \frac{\Delta_{\text {lat }}}{x} \cos \alpha$

The internal dissipated energy (Equation 17) is equated to the external work done by the external force (Equation 1). Then, $\Delta_{\text {lat }}$ is cancelled out and X, $\Delta_{\text {tip }}$ and $\Delta_{\text {axial }}$ are substituted by the Equations 8, 15-16 into the Equation 17. Hence, the load carrying capacity in failure Mode 4 is calculated as demonstrated in Equation 18.

$R_{4}=f_{h, \alpha} d \cos \alpha\left(2 \sqrt{\frac{M_{y}}{f_{h, \alpha}}+\frac{t^{2}}{2}}-t\right)+F_{a x, \alpha} \sin \alpha$

\subsection{Mode 5-double plastic hinge in screw}

The embedding strength of timber and bending yield moment of the fastener govern the load-carrying capacity in Modes 4 and 5 as the fastener displaces laterally and axially due to withdrawal and embedment forces. In Mode 5, the point of rotation defines the second plastic hinge. The distance between the plastic hinges $x$ is thus calculated in a similar way to that explained in Mode 4, using Equation 19.

$x=\sqrt{\frac{M_{Y}}{f_{h, a}}}$

The internal energy which is dissipated by the embedment of timber, withdrawal of screw and rotation of the plastic hinge is shown in equation 20 .

$W_{I}=f_{h, \alpha} d \cos \alpha \frac{\Delta_{\text {lat }}}{2}+F_{a x, \alpha} \Delta_{\text {axial }}+M_{y} \frac{\Delta_{\text {lat }}}{x} \cos \alpha$
The internal dissipated energy (Equation 20) is equated to the external work done by the external force (Equation 1). Then, as stated in Mode $4, \Delta_{\text {lat }}$ is cancelled out and $\Delta_{\text {axial }}$ and $x$ are substituted by Equations 8 and 19 into Equation 20. Hence, the load carrying capacity is represented by Equation 21 (

Figure 5).

$$
R_{5}=2 \cos \alpha \sqrt{f_{h, \alpha} M_{y} d}+F_{a x, \alpha} \sin \alpha
$$

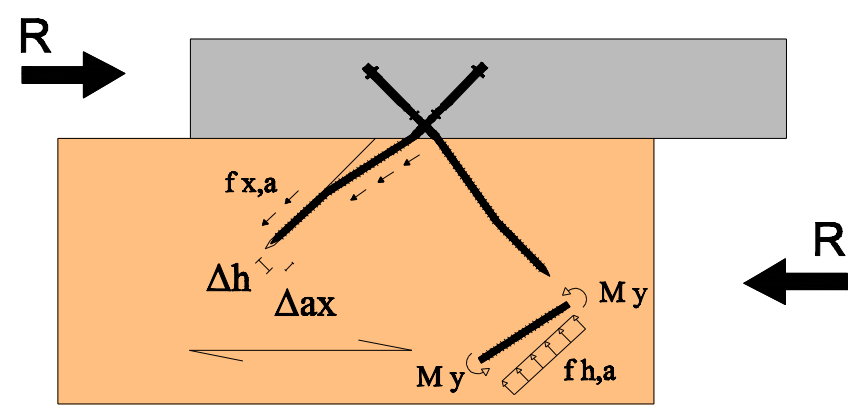

Figure 5 Mode 5 - double plastic hinge in screw.

\subsection{Mode 6- tensile failure of screw}

In addition, it is presumed two more shear and tensile failure modes of screw can occur at the timberconcrete interface, depending on the tensile strength of fastener. Tensile failure of the screw is calculated by Equation 22 as the axial strength of the joint depends on tensile capacity of screw. Hence, the load carrying capacity of the joint governed by the tensile failure of the fastener is obtained with Equation 23.

$R_{6}=\frac{F_{a x, \alpha}}{\sin \alpha}$

$R_{6}=\frac{f_{u} \pi d^{2}}{4 \sin \alpha}$

\subsection{Mode 7- shear failure of screw}

The shear failure of the screw at timber-concrete interface is identified to be the second failure mode which involves only the fastener. Higher inclination angles of screw to the grain direction of the timber, $\alpha$, increases the cross-sectional area $A_{\alpha}$ of the fastener at the timber-concrete interface as proposed in Equation 24.

$A_{\alpha}=\frac{\pi d^{2}}{4 \cos \alpha}$

Assuming that the shear yield stress of the screw is $0.6 f_{u}$, the load carrying capacity corresponding to shear failure is calculated with Equation 25 (Symon et al. 2010).

$R_{7}=0.6 f_{u} A_{\alpha}=\frac{0.6 f_{u} \pi d^{2}}{4 \cos \alpha}$ 


\section{EXPERIMETAL TEST}

The experimental aspect of the research consists of push-out tests of five TCC joint specimens using crossed $\left( \pm 45^{\circ}\right)$ screws (SFS Intec), Laminated Veneer Lumber (LVL) and conventional concrete.

The SFS screws introduced by Meierhofer (1992) in the early 1990's have been recognised as one of the first specific shear connections for TCC Structures. The fastener consists of two parts with a diameter of $6 \mathrm{~mm}$ as an anchor in the concrete and another threaded $165 \mathrm{~mm}$ long with outer diameter of $7.5 \mathrm{~mm}$ as the anchor in the wood as shown in

Figure 6 (Lukaszewska 2009).

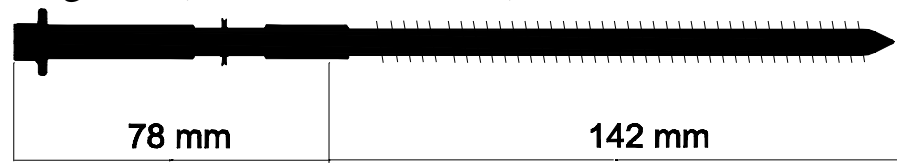

embedded part in concrete embedded part in LVL

Figure 6 SFS Intec VB-48-7.5x 165 screw.

Typical geometry and details of TCC's specimens are depicted in

Figure 7.

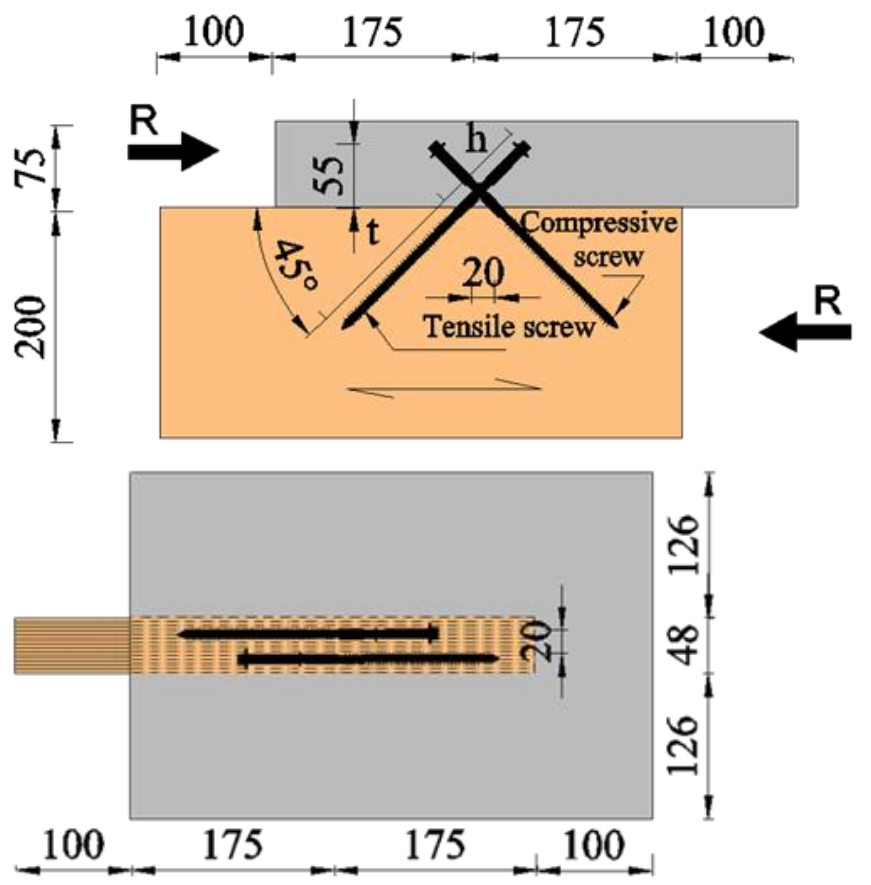

Figure 7 (a) cross-section and (b) plan view of specimen (mm).

In the push-out tests the load was applied onto the end of the timber component whilst the concrete slab, fixed on the table of the testing rig, resisted the load. The test aimed to derive the strength and stiffness of the connection. A load cell and Linear Variable Differential Transducers (LVDT) were applied to measure the load and relative displacement between the timber and concrete (
Figure 8). The load-slip diagrams of TCC joints obtained by push out test are displayed in

Figure 9.

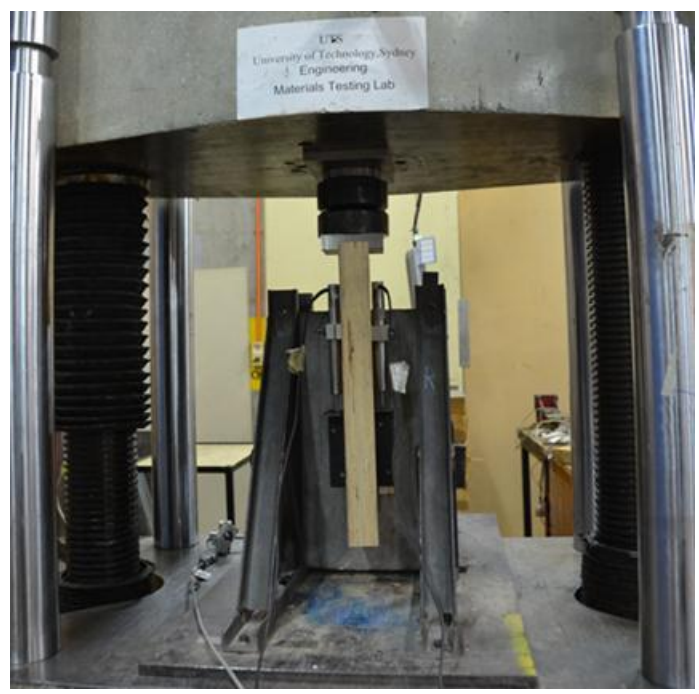

Figure 8 Set-up of a Test Specimen in the Test Rig.

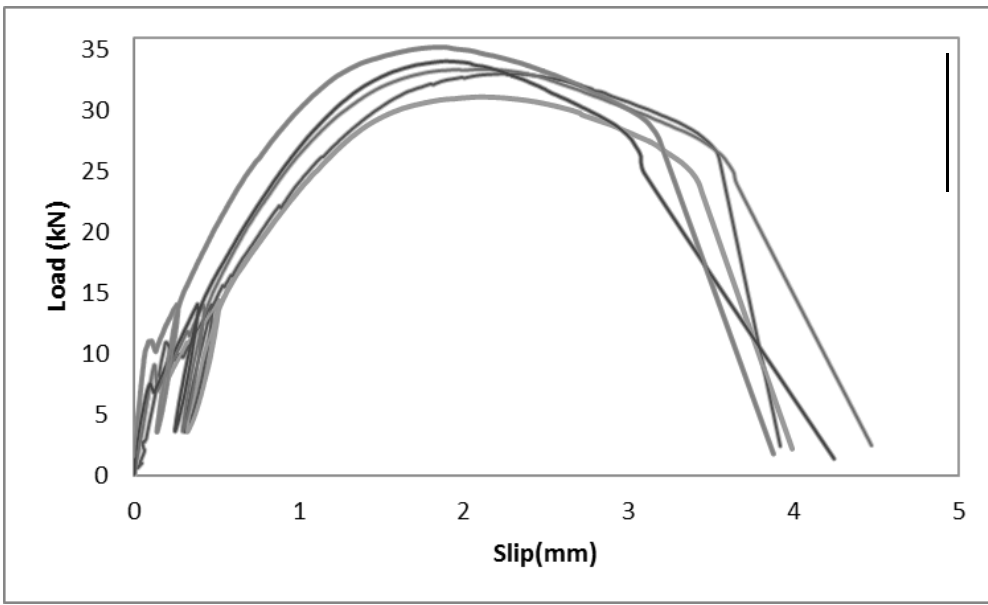

Figure 9 Load-slip diagrams of SFS VB-48-7.5x 165 screw.

\section{COMPARISON OF MODEL PREDICTION AND EXPERIMENTAL RESULT}

The equations of the plastic collapse model for seven different failure modes are presented in Section 2. The analytical model predicts that the tensile failure of screw in tension (Mode 6, Fu $=29.7 \mathrm{kN}$ ) should govern the load carrying capacity of the joint. The experimental test quantified the load carrying capacity of the joint at $33.4 \mathrm{kN}$ (average value), representing a difference of $12 \%$ to the predicted value (

Table 2).

As seen in push out test result (

Figure 9), the behaviour of the TCC joints was reasonably consistent whereas, load increased steadily, slowing slightly before peaking. After peaking, load gradually reduced to around 80-90\% $F_{\max }$, before a sudden and complete failure (Moshiri et al. 2012). 
Table 1 summarises the connection geometry and material properties. A summary of the push-out test results and predictions of the plastic collapse model for strength of crossed $\left( \pm 45^{\circ}\right)$ SFS Intec VB-48-7.5x 165 screws in LVL is shown in

Table 2.

The analytical model predicts that the tensile failure of screw in tension (Mode $6, \mathrm{Fu}=29.7 \mathrm{kN}$ ) should govern the load carrying capacity of the joint. The experimental test quantified the load carrying capacity of the joint at $33.4 \mathrm{kN}$ (average value), representing a difference of $12 \%$ to the predicted value (

\section{Table 2).}

As seen in push out test result (

Figure 9), the behaviour of the TCC joints was reasonably consistent whereas, load increased steadily, slowing slightly before peaking. After peaking, load gradually reduced to around $80-90 \%$ $F_{\max }$, before a sudden and complete failure (Moshiri et al. 2012).

Table 1 Summary of material properties of TCC joint with SFS screw.

\begin{tabular}{ll}
\hline $\begin{array}{l}\text { Material properties of TCC joint with SFS } \\
\text { screw }\end{array}$ & Value \\
\hline embedment depth in timber, $t(\mathrm{~mm})$ & 142 \\
Shank diameter of screw, $d(\mathrm{~mm})$ & 4.6 \\
charactersitic density of LVL, $\rho k\left(\mathrm{~kg} / \mathrm{m}^{3}\right)$ & 600 \\
Measured tensile stress of screw, $f_{u}(\mathrm{Mpa})$ & 1265 \\
yield moment of SFS screw, $M_{y}(\mathrm{~N} . \mathrm{mm})$ & 20050 \\
Calculated embedment strenght, $f_{h, 0}(\mathrm{kN})$ & 46.7 \\
Calculated withdrawal strenght, $f_{x, 0}(\mathrm{kN})$ & 52.9 \\
\hline
\end{tabular}

Table 2 Summary of push-out test results and predictions for crossed $\left( \pm 45^{\circ}\right)$ SFS Intec VB-48-7.5x 165 screws in LVL.

\begin{tabular}{ccccccccc}
\hline $\begin{array}{c}\text { Load } \\
\text { capacity } \\
(\mathrm{kN})\end{array}$ & $\begin{array}{c}\mathrm{Fmax} \\
(\mathrm{kN})\end{array}$ & $\begin{array}{c}\mathrm{R} 1 \\
(\mathrm{kN})\end{array}$ & $\begin{array}{c}\mathrm{R} 2 \\
(\mathrm{kN})\end{array}$ & $\begin{array}{c}\mathrm{R} 3 \\
(\mathrm{kN})\end{array}$ & $\begin{array}{c}\mathrm{R} 4 \\
(\mathrm{kN})\end{array}$ & $\begin{array}{c}\mathrm{R} 5 \\
(\mathrm{kN})\end{array}$ & $\begin{array}{c}\mathrm{R} 6 \\
(\mathrm{kN})\end{array}$ & $\begin{array}{c}\mathrm{R} 7 \\
(\mathrm{kN})\end{array}$ \\
\hline $\begin{array}{c}\text { Experimental } \\
\text { result }\end{array}$ & 33.4 & - & - & - & - & - & 33.4 & - \\
$\begin{array}{c}\text { Analytical } \\
\text { model }\end{array}$ & 29.7 & 122.8 & 43.2 & 98.5 & 69.2 & 64 & 29.7 & 35.6 \\
Error & $12 \%$ & & & & & & & \\
\hline
\end{tabular}

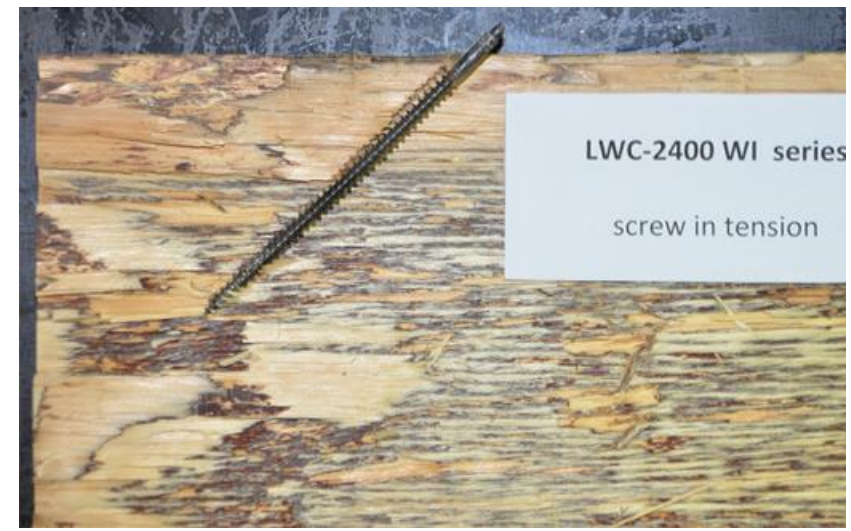

Figure 10 Opened TCC specimen connected by SFS screw.

In all specimens, a tensile failure of the screw with some shear contribution was observed. Open specimens as shown in

Figure 10 indicated necking of the failed screws and the undamaged concrete. Furthermore, the screws failed at their narrowest point, located 20$30 \mathrm{~mm}$ above the thread and embedded in the concrete. Such failure mode agrees with Mode 6 of kinematic plastic collapse model. This reinforced the good agreement between the experimental results and the prediction.

\section{CONCLUSION}

This paper presents a model for the strength of TCC joint using crossed $\left( \pm 45^{\circ}\right)$ proprietary screws (SFS Intec). The Johansen yield theory is extended to derive the strenght model of TCC joint with crossed $\left( \pm 45^{\circ}\right)$ screws which are loaded in tension and compression. The model is an upper bound plastic collapse model that assumes that the behaviour of the timber and screw is perfectly plastic and the concrete remains undamaged. The failure modes considers of the yield of the screw in tension and/or shear, and a series of combined failure modes such as screw withdrawal, lateral crushing of the timber and the development of plastic hinges in the screw. The experimental aspect of the research consists of push-out tests and verifies the strength model of TCC joints with inclined screws. The failure modes are also investigated. The model seems to accurately in predict both the ultimate strength and failure mode. This research suggests the model is reliable and can be used for the design of TCC floor with inclined SFS screws.

\section{ACKNOWLEDGEMENT}

The authors wish to acknowledge the financial support of Structural Timber Innovation Company (STIC). 


\section{REFERENCES}

Branco, J.M., Cruz, P.J.S. \& Piazza, M. 2007, 'Experimental analysis of laterally loaded nailed timber-to-concrete connections', Construction and Building Materials, vol. 23, no. 1, pp. 400-410.

Clouston, P., Bathon, L.A. \& Schreyer, A. 2005, 'Shear and Bending Performance of a Novel Wood--Concrete Composite System', Journal of Structural Engineering, vol. 131, no. 9, pp. 1404-1412.

Kavaliauskas, S. \& Kvedaras, A. 2010, 'The Predictive Model for Load-Carrying Capacity of Inclined Screws as Connecting-Links in Timber-Concrete Composite Beams', modern building materials,structures and techniques, Vilnius Lithuania.

Kavaliauskas, S., Kvedaras, A. \& Valiunas, B. 2007, 'Mechanical behaviour of timber-to-concrete connections with inclined screws', Journal of Civil engineering and Management, vol. 8, no. 3, pp. 193-199.

Kieslich \& Holschemacher 2010, 'Composite constructions of timber and high-performance concrete', Advanced material research, vol. 133 - 134, pp. 1171-1176.

Lukaszewska, E. 2009, 'Development of Prefabricated TimberConcrete Composite Floors', Universitetstryckeriet, Luleå, Lulea.

Meierhofer, U. 1992, 'a new efficient system for timber/concrete composite structural elements. Test, research and development', the IUFRO S5.02 Timber Engineering Conference pp. pp. 383-393.

Moshiri, F., Garven, C., Gerber, C., Valipour, H.R., Shrestha, R. \& Crews, K. 2012, 'An investigation on tcc systems using light-weight concrete', paper presented to the world conference on timber engineering(WCTE), Aukland, New Zealand.

Symon, D., Persaud, R. \& Stanislaus, H. 2010, 'Strength of inclined screw shear connections for timber and concrete composite construction', The Structural Engineer, vol. 88, no. 1 , pp. 25-32. 